\title{
Effect of Transdisciplinary Approach in Group Therapy to Develop Social Skills for Children with Autism Spectrum Disorder
}

\author{
Rajeev Ranjan \\ Rehabilitation Services, Society for the Physically Disabled, 2 Peng Nguan Street, SPD Ability Center, Singapore \\ Kajal Ray Pradhan \\ Rehabilitation Services, Society for the Physically Disabled, 2 Peng Nguan Street, SPD Ability Center, Singapore \\ Joyce Wong \\ Rehabilitation Services, Society for the Physically Disabled, 2 Peng Nguan Street, SPD Ability Center, Singapore
}

\begin{abstract}
The social impairments in individuals with Autism spectrum disorder (ASD) are diverse and involve speech, linguistic conventions and interpersonal interaction. 5 male children with ASD in the age range of 8 to 10 years were selected randomly. All the children were attending mainstream schools, receiving individual speech therapy and occupational therapy (45-minute session every fortnight) and were having difficulty in social interaction. The children were placed in a 3-hour group therapy program for 6 sessions, which were facilitated by two professionals, a speech-language therapist and an occupational therapist at our center (Society for the Physically Disabled). The rating score was rated by parent and therapist. The comparative pre and post therapy score among the two groups, that is by parents and therapist shows that the objectives for the group therapy were rated higher after the completion of the group therapy. Wilcoxon Signed Ranks Test shows there is significant difference $(\mathrm{P}<0.05)$ observed between pre and post group therapy rating scale by parents and therapist.
\end{abstract}

Index Terms — social skills, ASD, group therapy, children, parents, therapist

\section{INTRODUCTION}

Autism spectrum disorder is characterized by persistent deficits in social communication and social interaction across multiple contexts, including deficits in social reciprocity, nonverbal communicative behaviors used for social interaction and skills in developing, maintaining and understanding relationships, DSM (2013). As per Carter A S, Davis N O, and Volkmar F R. (2005), socialization deficits are a major source of impairment regardless of cognitive or language ability for individuals with ASD. The social impairments in individuals with ASD are diverse and involve speech, linguistic conventions and interpersonal interaction.

McConnell S R. (2002) states social skills training are a type of child specific intervention. The researchers, Cooper M J, Griffith K G and Filer J (1999) reported that the specific intervention involves teaching specific skills (e.g., maintaining eye contact, initiating conversation) through behavioral and social learning techniques. Social skill training has been reported to be an effective component of treatment regimens for many childhood disorders including childhood social phobia, Spence S. H, Donovan C and Brechman-Toussaint M. (2000) and specific learning disabilities, Forness S and Kavale K (1999). Barry T D, Klinger L G, Lee J M, Palardy N, Gilmore T and Bodin S D (2003) states that group based social skills training is an interesting intervention approach for use with children with ASD because it provides the opportunity to practice newly learned skills in a relatively naturalistic format that may promote interaction with other children.

With the increasing knowledge of autism since it's broadening of definition in 1995, there have also been increases in the number of interventions introduced to the field. One of which is DIR®, also referred to as Floortime, a developmental approach designed by Greenspan and Wieder (1998), increases independently initiated social interactions and social reciprocity.

Greenspan S and Wieder S (1999) defines DIR® is a developmental form of psychotherapy, which works by assisting the child through various stages of socialization leading to higher levels of communication. DIR $®$ is used to build social connections and reciprocity between the teacher and student. By building social reciprocity the teacher is able to engage the child at their motivation level to interact in the instructional process. The six stages of DIR® are as follows: The first stage of social-emotional development has been termed Attention and Regulation. The second stage of social-emotional development is Engagement. The third stage is two way communications. The fourth stage is Complex Problem-Solving and Communication. The fifth and sixth stages are called Forming Emotional Ideas and Building logical bridges between ideas (Logical Reasoning) respectively. 
Following which there are other interventions such as Sensory Integration and Group therapy. Sensory Integration is the neurological process that organizes sensation from one's own body and from the environment and makes it possible to use the body effectively within the environment. The spatial (space) and temporal (time) aspects of the inputs, from different sensory modalities are interpreted, associated, and unified, Ayres A J (1989). Dr. Ayres an Occupational Therapist in the USA is a pioneer in the treatment of children with specific learning and motor organization problems. She found that directing and controlling the inputs of different senses (i.e. sensory input through touch, body movement, vision, hearing, etc.) through Sensory Integration Therapy, children were able to learn and organize behavior more effectively at home and school, Ayres A J (1972).

At our pediatric rehabilitation services some of the children attending mainstream school have difficulties in social skills such as socializing with their peers, making friends, etc. So to overcome the challenges, they attend our center's individual Occupational and Speech Therapy services.

As, individual therapy focusses on child's pre-linguistic skills (eye to eye contact, focusing), linguistic skills (comprehension, expression), fine and gross motor skills. This helps the child to develop his/her functional communication in day to day routine. Therefore, there are no opportunities to practice their social interaction skills.

Group therapy is a therapeutic strategy in which a group of children of similar challenges or of homogeneous features meets for several sessions under the guidance and direction of a therapist (called a conductor, leader or facilitator). Davis RG (1948) described group therapy to help children gain social acceptance in the first grade. During a typical group therapy session, children are facilitated to socialize with their peers, initiate and/ or participate in the group play or express their potential. Bandura A (1989) suggested that most social learning takes place by observing others (Others means Persons in the child's immediate social environment, i.e. Parents, Siblings, Teachers and Peers). Group therapy may be practiced in a variety of settings such as therapist's clinic, special school, children's developmental center etc. In the group therapy session children get opportunities to practice their social interaction skills with other children of their age group in a safe environment. These social skill "practices" will build up their confidence level to initiate and interact with their peers. The children will also get the opportunities to practice appropriate social behavior within the group.

Groups usually meet weekly, and the duration of therapy may vary. For some cases, group therapy can last for a few months, whereas others may attend group therapy for a few years. Rhodes SL (1973) worked on behavioral modification by using a short term work which is six to eight sessions. The frequency and duration of group therapy often depend on many factors, including the severity of the clients' conditions and/or problems as well as the results sought by the therapist.

With all these intervention approaches in combination, SPD's pediatric rehabilitation department piloted the first single session group therapy program on $25^{\text {th }}$ June 2010 followed by the 6 sessions of group therapy series from September 2010 to Feb 2011.

Both the Occupational Therapist (OT) and Speech Therapist (ST) facilitated the group together and each complementing their professional strategies while running the group as in a transdisciplinary approach. The transdisciplinary approach is a framework for allowing members of an educational team to contribute knowledge and skills, collaborate with other members, and collectively determine the services that would most benefit a child. According to Bruder (1994) "This approach integrates a child's developmental needs across the major developmental domains" and "involves a greater degree of collaboration than other service delivery models".

The group therapy program was a platform for the children to develop their social interaction as well as to monitor their progress.

Aim of the study was,

1. To see the impact of Transdisciplinary approach in group therapy to develop social interaction skills for children with Autism Spectrum Disorders (ASD)

2. To see the effect of incorporating the Occupational therapy and Speech \& language therapy approaches in group therapy sessions.

3. To see the impact of standardized treatments such as DIR/Floor Time and Sensory Integration in group therapy to improve Social interaction skills for children with Autism Spectrum Disorders(ASD)

\section{METHOD}

Participants: 5 male children diagnosed with ASD in the age range of 8 to 10 years, The Parent (either Father or Mother) of each child was selected for the study. The children were in lower primary i.e. Primary 1-4. All the children were attending mainstream school and receiving individual speech therapy and occupational therapy (45 minute session every fortnight) and having difficulty in social interaction.

Tools of the study: A four point rating scale was developed to monitor the child's progress in the group therapy, The Rating criteria and points are as follows

- 1- The child who needs maximum prompt, i.e. visual, verbal and physical guidance from the therapist,

- 2- The child who needs moderate prompt, i.e. visual, and verbal cues from the therapist,

- 3- The child who needs minimal prompt, i.e. verbal cues from the therapist and

- 4- The child who does not need any prompt and is independent. 
The objectives of the rating scale for the group therapy program are as follows:

1. Listen and follow the instructions

2. Interact with other children in the group

3. Initiate in the activity

4. Initiate and maintain interaction

5. Initiate and complete activities

Procedure: The children were engaged in a 3 hour group therapy program for 6 sessions. The sessions were planned once in a month, which was facilitated by the speech therapist and occupational therapist. A total of 5 activities were planned to meet the objectives of the group therapy. Strategies from standardized treatments such as DIR/Floor Time and Sensory Integration were adopted in the group therapy. The rating scale was scored both by the parent (of each child) and the therapist before and after the group therapy session. Each objective was scored on a four point rating scale.

The scores from the pre and post therapy were compared to monitor the overall performance of the child on each objective.

Statistics Involved: Mean and standard deviation was obtained using SPSS version 16. Wilcoxon Signed Ranks Test was used to find if any significant difference exist among the pre and post therapy rating score.

\section{RESULTS}

The study aimed to see the impact of Transdisciplinary approach in group therapy to develop social interaction skills for children with Autism Spectrum Disorders (ASD). The rating scale was scored by both the parent and the therapist. The result of the post therapy rating score was higher than the pre therapy score.

The results of the pre and post therapy rating scores are shown below.

TABLE 1

SHOWS THE PRE AND POST RATING SCORE BY PARENT FOR ALL THE CHILDREN AND THE P VALUE OF THE SCORES.

\begin{tabular}{|c|c|c|c|c|c|c|c|c|c|c|c|}
\hline \multirow[b]{3}{*}{ Objectives } & \multicolumn{10}{|c|}{ Parent Scores } & \multirow[b]{3}{*}{ P Value } \\
\hline & \multicolumn{5}{|c|}{ Pre Therapy } & \multicolumn{5}{|c|}{ Post Therapy } & \\
\hline & $\begin{array}{l}\text { Ch } \\
\text { A }\end{array}$ & $\begin{array}{l}\text { Ch } \\
\text { B }\end{array}$ & $\begin{array}{l}\text { Ch } \\
\text { C }\end{array}$ & $\begin{array}{l}\text { Ch } \\
\text { D } \\
\end{array}$ & $\begin{array}{l}\text { Ch } \\
\text { E } \\
\end{array}$ & $\begin{array}{l}\text { Ch } \\
\text { A } \\
\end{array}$ & $\begin{array}{l}\text { Ch } \\
\text { B } \\
\end{array}$ & $\begin{array}{l}\text { Ch } \\
\text { C } \\
\end{array}$ & $\begin{array}{l}\text { Ch } \\
\text { D } \\
\end{array}$ & $\begin{array}{l}\text { Ch } \\
\text { E } \\
\end{array}$ & \\
\hline Listen and Follow instructions & 2 & 3 & 3 & 2 & 4 & 4 & 4 & 4 & 3 & 4 & .059 \\
\hline Interact with other children in the group & 2 & 1 & 3 & 1 & 3 & 3 & 3 & 4 & 3 & 3 & .063 \\
\hline Initiate in the activity & 2 & 2 & 3 & 2 & 2 & 3.5 & 3 & 4 & 2 & 3 & .059 \\
\hline Initiate and maintain interaction & 2 & 1 & 2 & 2 & 2 & 3 & 3 & 3 & 3 & 3 & .034 \\
\hline Initiate and complete activities & 2 & 2 & 2 & 2 & 2 & 3 & 3.5 & 3 & 3 & 3 & .034 \\
\hline
\end{tabular}

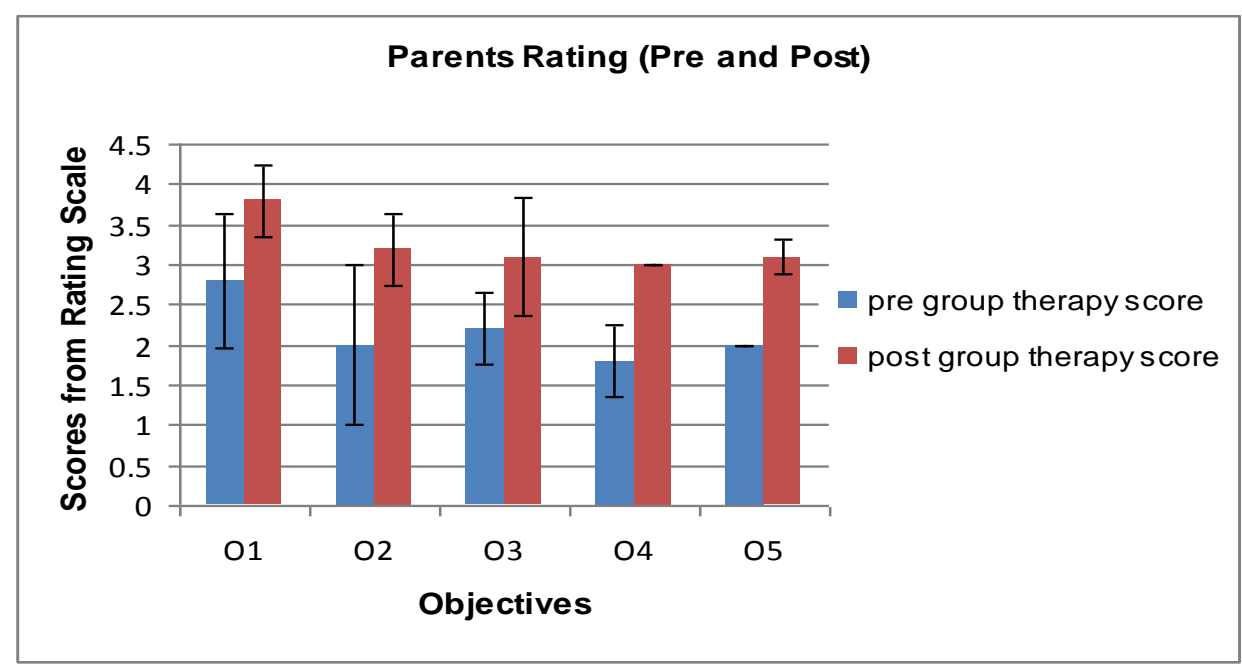

Graph 1: shows pre and post Parent rating scale for different Objectives

Wilcoxon Signed Ranks Test showed, that there was a significant difference $(\mathrm{P}<0.05)$ observed between pre and post group therapy rating scale by the parent in the objective numbered 4 and 5 . However, there was no significant difference observed in pre and post rating scale by the parent for the objectives numbered 1, 2 and 3 . The objectives numbered 1, 2 and 3 although had no significant difference; it was nearly at the significance level. 
TABLE 2

SHOWS THE PRE AND POST RATING SCORE BY THERAPIST FOR ALL THE CHILDREN AND THE P VALUE OF THE SCORES

\begin{tabular}{|c|c|c|c|c|c|c|c|c|c|c|c|}
\hline \multirow[b]{3}{*}{ Objectives } & \multicolumn{10}{|c|}{ Therapist Scores } & \multirow[b]{3}{*}{ P Value } \\
\hline & \multicolumn{5}{|c|}{ Pre Therapy } & \multicolumn{5}{|c|}{ Post Therapy } & \\
\hline & $\begin{array}{l}\text { Ch } \\
\text { A }\end{array}$ & $\begin{array}{l}\text { Ch } \\
\text { B }\end{array}$ & $\begin{array}{l}\text { Ch } \\
\text { C }\end{array}$ & $\begin{array}{l}\text { Ch } \\
\text { D } \\
\end{array}$ & $\begin{array}{l}\text { Ch } \\
\text { E }\end{array}$ & $\begin{array}{l}\text { Ch } \\
\text { A }\end{array}$ & $\begin{array}{l}\text { Ch } \\
\text { B }\end{array}$ & $\begin{array}{l}\text { Ch } \\
\text { C }\end{array}$ & $\begin{array}{l}\text { Ch } \\
\text { D } \\
\end{array}$ & $\begin{array}{l}\text { Ch } \\
\text { E }\end{array}$ & \\
\hline Listen and Follow instructions & 2.8 & 3.5 & 4 & 3 & 4 & 4 & 4 & 4 & 3.6 & 4 & .109 \\
\hline Interact with other children in the group & 2 & 2 & 3 & 2.75 & 3 & 3 & 3 & 4 & 2.8 & 4 & .034 \\
\hline Initiate in the activity & 2.4 & 2.2 & 3.5 & 2.5 & 3 & 3.4 & 3.6 & 4 & 3.2 & 4 & .042 \\
\hline Initiate and maintain interaction & 2 & 2.2 & 3 & 2 & 2.4 & 3.2 & 3.2 & 3.8 & 3 & 4 & .042 \\
\hline Initiate and complete activities & 2 & 2.2 & 3 & 2.25 & 2.6 & 3.4 & 3.4 & 4 & 3 & 4 & .042 \\
\hline
\end{tabular}

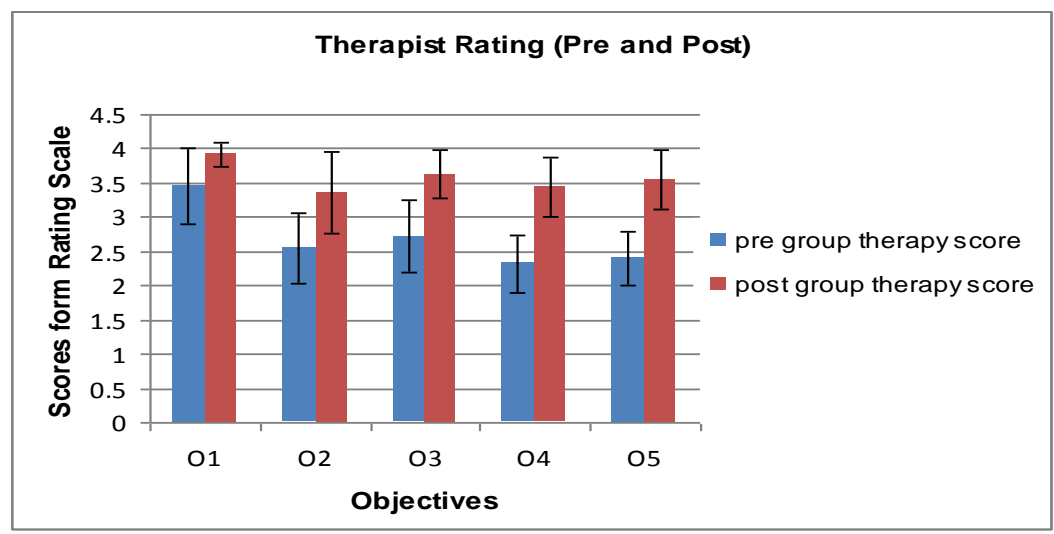

Graph 2: shows pre and post rating scale by therapist for different Objectives

The above graph indicates the pre and post therapy score which has been scored by parents. The post group therapy scores are higher in each objective, which shows there was improvement. Wilcoxon Signed Ranks Test showed, that there was a significant difference $(\mathrm{P}<0.05)$ observed between pre and post group therapy rating scale by the therapist in the objectives numbered 2, 3, 4 and 5. However, there was no significant difference observed in pre and post rating scale by the therapist for the $1^{\text {st }}$ objective.

The result shows there was an impact of Transdisciplinary approach in group therapy to develop social skills in children with ASD. The children in the group showed improvement after the six sessions of the group therapy.

\section{DISCUSSION}

This study mainly shows the overall performance of the child in a group where transdiciplinary approach was used to facilitate the social interaction (objectives), and the rating was done by both parent and therapist before and after the group session.

The comparison of pre and post rating scores are discussed below.

Objective one: Up to $30 \%$ improvement recorded by the therapist and $50 \%$ improvement observed by the Parent for child A. There was 25\% improvement observed by Parents and almost $15 \%$ improvement recorded by the therapist for the child B. Only $25 \%$ improvement observed by the Parent and no improvement were recorded by the therapist in child C. Both the parent and therapist observed $25 \%$ improvement for the child D and there were no improvement was observed by both parents and the therapist in child E. These improvements noted for each child indicate up to $15 \%$ to $30 \%$ improvement in the objective one of the study-Listen and Follow instructions.

Objective two: Both the parents and the therapist observed improvement by $25 \%$ in child A. There was $50 \%$ improvement observed by parent and $25 \%$ improvement recorded by therapist for child B. Both the parent and the therapist recorded improvement by $25 \%$ in the child $\mathrm{C}$. There were $50 \%$ improvement observed by the parent and minimal improvement (up to $5 \%$ only) was recorded by the therapist for child D. Up to $25 \%$ improvement was recorded by the therapist and no improvement was observed by the parent in child E. These improvements noted for each child indicate up to $5 \%$ to $50 \%$ improvement in the objective two of the study-Interact with other children in the group.

Objective three: $37.5 \%$ improvement was observed by the parent and up to $15 \%$ improvement was recorded by the therapist for child A. There was 50\% improvement observed by the parent and up to $35 \%$ improvement was recorded by the therapist for child B. Up to $25 \%$ improvement was observed by the parent and up to $15 \%$ improvement was recorded by the therapist in child C. A Minimal improvement of $12 \%$ was observed by the therapist. However, the parent reported no specific improvement for child D. Both groups observed similar improvement $(25 \%)$ in child E. These improvements noted for each child indicate up to $12 \%$ to $50 \%$ improvement in the objective three of the studyInitiate in the activity.

Objective four: Both groups reported improvement for child A, i.e. $30 \%$ from the therapist and up to $25 \%$ from the parent. Up to $50 \%$ improvement was observed by the parent and $25 \%$ improvement was recorded by the therapist for child B. Both the groups observed improvement up to $25-30 \%$ for child C. There was $25 \%$ improvement observed by 
both groups for the child D. Up to $40 \%$ improvement was recorded by the therapist and up to $25 \%$ improvement was observed by the parent in the child E. These improvements noted for each child indicate up to $25 \%$ to $50 \%$ improvement in the objective four of the study-Initiate and maintain interaction.

Objective five: Up to $35 \%$ improvements were recorded by the therapist and up to $25 \%$ improvement was observed by the parent for the child A. Both groups observed similar improvement (up to 35 to $40 \%$ ) in child B and similar improvement (up to 25 to $30 \%$ ) for the child C \& D. Up to $35 \%$ improvement was recorded by the therapist and $25 \%$ improvement was observed by the parent in child E. These improvements noted for each child indicate up to $25 \%$ to $35 \%$ improvement in the objective five of the study-Initiate and complete activities.

This study involved 5 children in a group for 6 sessions. Since this study has very limited participants and fewer sessions, the results cannot be generalized to the general population of children of the same age group and diagnosis in Singapore. Further studies involving a larger sample may be required. The limitation of this study is inter-child, interparent and inter-therapist rating scores of the objectives. White S W, Keonig K and Scahill L (2007) mentioned in their study for children with ASD that, the necessity of an outcome measurement should be socially valid and sensitive to change. They also added that the outcome measurement should have the strength to measure the child's learnt new specific skills in context to both treatment and in real environment.

Overall, the children in the group showed improvement in social-communication with their peers, showed interest to participate, initiated and took turns in storytelling, various art and craft activities. This study signifies that transdiciplinary approach in group therapy is a useful treatment strategy to facilitate children to initiate and interact with their peers.

\section{CONCLUSIONS}

From the study it is concluded that the individual therapy may have limitation on socialization, where as a group therapy facilitates a conducive social environment for children with ASD. In the group therapy session children have opportunities to practice their social interaction skills with other children of their age group in a safe environment. This enhances their confidence levels to initiate and interact with their peers. Hence, transdisciplinary approach in group therapy plays a significant role to develop social interaction skills for children with autism. It also provided a platform for the children to be exposed to different professionals with various treatment strategies.

\section{APPENDIX A. RATING CRITERIA FOR THE OBJeCTIVES OF CHILD’s PERFORMANCE IN THE GROUP THERAPY}

\section{Rating Scales for the objectives of child's performance in the group therapy}

Child Name:

Date:

\begin{tabular}{|c|c|c|c|c|c|c|c|c|c|c|c|c|c|c|c|c|c|c|c|c|c|c|}
\hline \multirow[t]{3}{*}{ SN } & \multirow{3}{*}{ Ratings } & \multicolumn{21}{|c|}{ Performance of the child in the Activities } \\
\hline & & \multicolumn{4}{|c|}{ Activity-1 } & \multicolumn{4}{|c|}{ Activity-2 } & \multicolumn{4}{|c|}{ Activity-3 } & \multicolumn{4}{|c|}{ Activity-4 } & \multicolumn{4}{|c|}{ Activity-5 } & \multirow{2}{*}{$\begin{array}{l}\text { Average } \\
\text { Rating }\end{array}$} \\
\hline & & 1 & 2 & 3 & 4 & 1 & 2 & 3 & 4 & 1 & 2 & 3 & 4 & 1 & 2 & 3 & 4 & $\mathbf{1}$ & 2 & 3 & 4 & \\
\hline 1 & $\begin{array}{l}\text { Listen and Follow } \\
\text { instructions }\end{array}$ & & & & & & & & & & & & & & & & & & & & & \\
\hline 2 & $\begin{array}{l}\text { Interact with other } \\
\text { children in the group }\end{array}$ & & & & & & & & & & & & & & & & & & & & & \\
\hline 3 & Initiate in the activity & & & & & & & & & & & & & & & & & & & & & \\
\hline 4 & $\begin{array}{l}\text { Initiate and maintain } \\
\text { interaction }\end{array}$ & & & & & & & & & & & & & & & & & & & & & \\
\hline 5 & $\begin{array}{l}\text { Initiate and complete } \\
\text { activities }\end{array}$ & & & & & & & & & & & & & & & & & & & & & \\
\hline & Total & & & & & & & & & & & & & & & & & & & & & \\
\hline
\end{tabular}

Explanatory notes for the Rating scale:

- Rating scale 1 is equivalent to $25 \%$ - The child who needs maximum prompt, i.e. visual, verbal and physical guidance from the therapist.

- Rating scale 2 is equivalent to $50 \%$ - The child who needs moderate prompt, i.e. visual, and verbal cues from the therapist.

- Rating scale 3 is equivalent to $75 \%$ - The child who needs minimal prompt, i.e. verbal cues from the therapist.

- Rating scale 4 is equivalent to $100 \%$ - The child who don't need any prompt and able to perform him/herself.

\section{ACKNOWLEDGEMENT}

Our Sincere Thanks to, SPD Executive Director, Mr. Pal for his kind approval for the clinical study and the training grant from Society for the Physically Disabled, Singapore. All clients and parents for their consent and active participation in the research study. Ms. Debbie Chow and Ms Tay Hwee Lin for their guidance and encouragement; Mr. Kumar for his statistical analysis; Mrs. Thrived, Ms. Petra, Mrs. Wencina and all support staff at SPD for their constant help throughout the entire clinical study. 
Note: conflict of interest

The First author has attended the training on DIR®/ Floor time, so the strategies from DIR/ floor time were incorporated during the activity session for the group therapy, and also the author is pursuing Part time $\mathrm{PhD}$ in Audiology and Speech-Language Pathology from Maharashtra University of Health Sciences, Nasik, India. The statistician was hired and remunerated by the author for doing statistical analysis, in which SPSS version 16 was used for data analysis.

\section{REFERENCES}

[1] American Psychiatric Association. (2013). Diagnostic and statistical manual of mental disorders (5th ed.). Arlington, VA: American Psychiatric Publishing.

[2] Ayres, A.J. (1989). Sensory integration and Praxis test. Los Angeles, CA: Western Psychological services.

[3] Ayres, A.J. (1972). Sensory integration and learning disorders. Los Angeles, CA: Western Psychological services.

[4] Barry, T. D., Klinger, L. G., Lee, J. M., Palardy, N., Gilmore, T., \& Bodin, S. D. (2003). Examining the effectiveness of an outpatient clinic-based social skills group for high-functioning children with autism. Journal of Autism and Developmental Disorders, 33, 685-701.

[5] Bandura, A. (1989). Social Cognitive Theory. In R.Vasta (Ed), Annals of child development, vol.6. Six theories of child development (PP.1-60). Greenwich, CT: JAI Press.

[6] Bruder, M.B. (1994). Working with members of other disciplines: Collaboration for success. In M. Wolery \& J.S. Wilbers (Eds.), including children with special needs in early childhood programs (pp. 45-70). Washington, DC: National Association for the Education of Young Children.

[7] Carter, A.S., Davis, N.O., \& Volkmar, F.R. (2005). Social development in autism, In F.R. Volkmar, R.Paul, A. Klin, \& D.Cohen (Eds.), Handbook of autism and pervasive development disorders: vol.1. Diagnosis, development, neurobiology, and behavior. Hoboken, NJ: John Wiley \& Sons.

[8] Cooper, M. J., Griffith, K. G., \& Filer, J. (1999). School intervention for inclusion of students with and without disabilities. Focus on Autism and Other Developmental Disabilities, 14, 110-115.

[9] Davis RG, (1948). Group therapy and social acceptance in a First-Second grade, Elementary school journal, December 1948, vol 49 (4), 219-223.

[10] Forness, S., \& Kavale, K. (1999). Teaching social skills in children with learning disabilities: A meta-analysis of the research. Learning Disability Quarterly, 19, 2-13.

[11] Greenspan S.I. \& Wieder (1998). The Child with Special Needs. Encouraging intellectual and emotional growth. Reading, MA: Perseus Publishing.

[12] Greenspan, S., \& Wieder, S. (1999). A Functional Developmental Approach to Autism Spectrum Disorders. Journal of the Association for Person with Severe Handicaps (JASH), 24(3), 147-161.

[13] McConnell, S. R. (2002). Interventions to facilitate social interaction for young children with Autism: Review of available research and recommendations for educational intervention and future research. Journal of Autism and Developmental Disorders, 32, 351-373.

[14] Rhodes SL, (1973). Short term groups of latency age children in a school setting. Int J Group, Psychother 23: 204-216.

[15] Spence, S. H., Donovan, C., \& Brechman-Toussaint, M. (2000). The treatment of childhood social phobia: The effectiveness of a social skills training-based, cognitive-behavioural intervention, with and without parental involvement. Journal of Child Psychology \& Psychiatry, 41, 713-726.

[16] White. S. W., Keonig. K. \& Scahill. L. (2007). Social Skills Development in Children with Autism Spectrum Disorders: A Review of the Intervention Research. Journal of Autism Developmental Disorders, 37(10), 1858-1868.

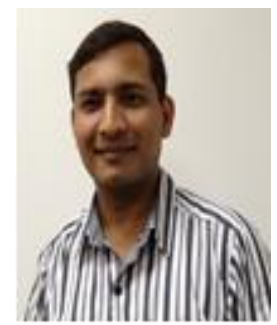

Rajeev Ranjan was born in Bihar, India on January $11^{\text {th }}$, 1979. He has his B.Sc. (Speech \& Hearing) from University of Mysore in 2001 and Master of Audiology and Speech Language Pathology from Mangalore University, Karnataka, India in 2006. Currently he is doing a part time PhD in Audiology and Speech Language Pathology from Maharashtra University of Health Sciences, Mumbai, India. His major certification includes AEPS, Hanen Program and PROMPT.

He has been practicing as a speech Therapist in Pediatric Rehabilitation Services at the Society for the Physically Disabled (SPD) since July 2007. Before joining SPD he had worked as an Audiologist and speechlanguage pathologist in Hospital, Rehabilitation center as well as in teaching institution in India for 5 Years. He has also teaching experience in teaching undergraduate student in the institution.

Mr. Ranjan is a registered therapist from Allied Health Professions Council, Singapore, Rehabilitation Council of India and also holds membership in Speech language and hearing Association Singapore, Cochlear implant group of India \& Indian speech and hearing Association. 


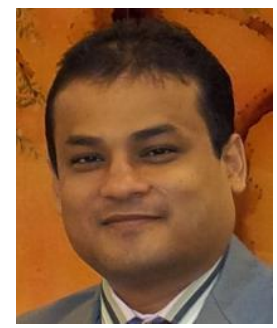

Kajal Ray Pradhan qualified as an occupational therapist in 2000 and holds a Bachelor degree in Occupational Therapy. He has completed his Masters of Clinical Rehabilitation from the Flinders University, South Australia. He is certified in Neuro Developmental Therapy from NDT Association, USA and is trained in Sensory Integration.

He has varied experience working in Singapore and abroad both in acute care hospital, special education school, early intervention programs, and private clinics. Kajal has wide experience as a pediatric occupational therapist treating various disabilities such as ASD, Global Developmental Delays, ADHD, Developmental Coordination Disorders, Cerebral Palsy, Down's syndrome, and Handwriting Difficulties.

Besides practice, Kajal is actively engaged in various parents/caregivers training programs and public talks. He also supervise trainee Occupational Therapist from the NYP school of health sciences, and from overseas.

Joyce Wong is a trained social worker. In addition Bachelor in Arts (Social Worker), she has a graduate diploma in business administration. Started as a Social Worker after graduating from National University of Singapore in 1994, she was involved in direct social work with people with disabilities. She brings with her 20 years of experience in direct social work as well as policy and service planning in various sectors including disability, eldercare and rehabilitation of ex-drug abusers. Currently the Acting Director for Services at the Society for the Physically Disabled (SPD), she plays an instrumental role in setting the direction and drives the development of programmes including adult rehabilitation centers, pediatric rehabilitation centers, early intervention services, therapy hub, and integration support for students with physical disabilities in mainstream schools, social work support services. 